\title{
Merleau-Ponty e Descartes: o afeto \\ ENTRE A MEDICINA E A PSICOLOGIA
}

\author{
Reinaldo Furlan*
}

\section{Resumo}

Através da noção de afeto, à luz da filosofia de Merleau-Ponty, busca-se problematizar a herança da metafísica cartesiana presente na medicina e na psicologia ocidentais. Em Descartes encontramos dois programas distintos de pesquisa para a Antropologia: um para o corpo, do qual se encarregou nossa medicina, e outro para a alma, do qual se encarregou nossa psicologia. Afinal, embora na Antropologia cartesiana o homem seja de fato a união substancial de corpo e alma, só se pode falar com clareza de um ou outro termo conforme os ditames de sua metafísica. Através da descrição do sentido da experiência do corpo próprio, Merleau-Ponty busca desconstruir as noções de corpo e alma em Descartes para explicitar essa união que a filosofia cartesiana reconheceu apenas de fato. A noçáo de sentir ou afeto é central nessa discussão, pois é a expressão privilegiada dessa união.

Palavras-chave: metafísica moderna; Merleau-Ponty; medicina; psicologia.

\section{Abstract \\ Merleau-Ponty and Descartes: the FeEling Between Medicine AND PSYCHOLOGY}

Based on the notion of feeling, according to the philosophy of Merleau-Ponty, the legacy of Cartesian metaphysics presence in western medicine and psychology is discussed. In Descartes we find two distinct programs of research: one for the body, which undertook our medicine, and another for the soul, which undertook our psychology. After all, although in the Cartesian Anthropology man is in fact the substantial union between body and soul, his metaphysical establishes that we

* Departamento de Psicologia e Educação, USP, Ribeirão Preto, São Paulo, Brasil. E-mail: reinaldof@ffclrp.usp.br. 
can just speak clearly about them separately. By describing the meaning of the experience of the own body, Merleau-Ponty seeks to deconstruct the notions of body and soul in Descartes, and point out this union that Descartes's philosophy recognized just in fact. The notion offeeling is the bottom line in this discussion, once it is the privileged expression of this union.

Keywords: modern metaphysics; Merleau-Ponty; medicine; psychology.

O homem é só um laço de relaçôes, apenas as relaçôes contam para o homem. (Merleau-Ponty, 1945/1994, p. 612)

\section{Objetivo}

O objetivo do artigo é mostrar, do ponto de vista ontológico ou epistemológico, decorrentes da modernidade, em particular da metafísica cartesiana, a situação da psicologia e da medicina em nossa sociedade. A metafísica cartesiana concebe o homem como união substancial entre corpo e alma, a partir da compreensão do corpo enquanto extensão e movimento e da alma enquanto pensamento. A noção de sentir ou afeto é central nessa discussão porque expressa a união de fato entre essas duas ordens de realidades. Nesse sentido, o sentir (afeto) encontra-se entre uma medicina que trata do corpo como se fosse um objeto e uma psicologia que trata das relaçóes de sentidos; entre uma medicina que atua através da farmacotécnica e uma psicologia que atua através da fala. Ambos, psicólogos e médicos, sabem que suas intervenções interferirão na maneira de sentir do homem, mas não é esse propriamente o objeto de suas competências: o médico atua de um lado, o psicólogo do outro.

Em síntese, o objetivo do artigo não é analisar a situação empírica da medicina e da psicologia em nossa sociedade, o que abriria para um campo heterogêneo de práticas e discursos, mas apresentar o contexto ontológico e epistemológico do sentido dessas práticas, decorrente da modernidade (No mesmo sentido, sob o viés da antropologia, cf. Le Breton, 2011).

A filosofia de Merleau-Ponty se destaca com a pretensão de revisar a compreensão metafísica cartesiana do homem, partindo justamente da descrição da experiência do corpo próprio. Nesse sentido, a intenção é problematizar os quadros da metafísica cartesiana através de sua filosofia. Não se trata de prescrever a mudança de um paradigma, que, como destacamos no artigo, faz parte de nossa forma de vida e, portanto, é aí que se decide, através de nossas práticas linguísticas, sua mudança ou reprodução, ou seja, no enfrentamento diário de suas questóes. Como se sabe, não se troca de paradigma (Kuhn, 1962/2009; Chalmers, 2000), menos ainda 
de forma de vida, em um ato isolado e de uma vez por todas. Ou seja, vivemos os paradoxos herdados da metafísica moderna, com suas potências e limitaçóes. Por isso terminamos o artigo abrindo mais suas questóes, procurando evitar, dessa forma, a sugestão simplificadora de que os problemas ou limitaçóes enfrentados por nossa medicina e psicologia são decorrentes de forma linear da metafísica moderna.

\section{Introdução}

Os quadros da metafísica cartesiana, que ainda expressam, provavelmente, a estrutura dominante de funcionamento de nossos pensamentos, quiçá de nossa forma de vida, estabelecem, de um lado, os objetos e suas relações de causa e efeito e, do outro, o pensamento, que está em relação com o mundo objetivo através de nosso corpo, que é o local, pois, da mistura dessas duas ordens de realidade. $\mathrm{O}$ movimento cartesiano (Descartes, 1641/1983) primeiro estabelece a divisão entre corpo e alma para depois afirmar a sua união no homem, que se reconhece de fato, mas não se compreende propriamente, visto que representa duas realidades de natureza distintas.

A fenomenologia de Merleau-Ponty (1945/1994) inverte esse movimento, partindo da descrição da experiência do corpo próprio (essa a que Descartes chegou após a divisão metafísica entre corpo e alma), para afirmar que a divisão entre corpo e alma é derivada de sua união para fins específicos da ciência moderna. Nesse sentido ganham destaque em sua filosofia 1) a percepção enquanto campo originário da nossa realidade, ou 2) a relação entre os corpos, revelada pela mesma. Embora a relação perceptiva entre os corpos dependa do que ocorre no cérebro ou no corpo de forma geral, neles não se encerra, porque o cérebro ou o corpo são na abertura de sentido na sua relação com o mundo. Em outros termos, a realidade do cérebro ou do corpo é para fora, completa-se com sua abertura ao mundo, sendo um desvirtuamento de sua realidade considerar o que está fora como se fosse uma imagem ou representaçáo no cérebro, assim como considerar o que está dentro - milhôes de células e reaçóes bioquímicas - sem sua relação com o fora. Ou ainda, o cérebro vivo, em funcionamento, em primeiro lugar faz parte de um corpo que é nas suas relaçóes com as coisas e os outros, das quais as relaçóes perceptivas se destacam. Em síntese, o cérebro ou o corpo são para a percepção do mundo, percepção que faz parte de sua realidade também e, assim, de nós mesmos; na verdade, como diz Merleau-Ponty, é onde a maior parte de nossa vida se realiza. E por isso não há eu sem mundo, e somos o nosso mundo ou o sentido que vivemos (Sartre, 1940/1976; Merleau-Ponty, 1945/1994). O que mostra que 
é preciso restituir a concretude que os sentidos têm, que não são simples ideias ou imagens à parte do que somos, mas a trama do tecido de nossas vidas.

Note-se bem, em Descartes (1641/1983) primeiro as ideias são reais, e a realidade externa dos corpos duvidosa; a seguir, sua metafísica afirma as duas ordens de realidade: corpo e espírito, ou objeto e pensamento; mas o cartesianismo não pôde impedir a evolução do objetivismo até as partes mais elevadas da alma (Merleau-Ponty, 1964), ou do materialismo em seu sentido mais redutor da matéria, que, por fim, degradou as ideias a simples imagens do real. Não se trata aqui de mostrar a incoerência desse movimento, que termina negando o próprio pensamento da ciência, ou, em sua tese contrária, o espiritualismo; afinal, ao menos o pensamento do cientista escapa a essa realidade objetiva na medida em que o compreende ou é sua condição de compreensão, e é por isso que Merleau-Ponty (1945/1994) dizia que o idealismo (enquanto ontologia) e o intelectualismo (enquanto epistemologia) eram mais consequentes filosoficamente do que o realismo (ontologia) ou o empirismo (epistemologia), que concebiam o sujeito como derivado das relaçóes objetivas do mundo.

Em termos da filosofia existencial, o que nos interessa é a compreensão do homem concreto, não as abstraçôes sobre o mesmo (a noção de "concreto" é muito importante para as filosofias de Sartre (1940/1976) e Merleau-Ponty (1945/1994), sobretudo a partir da crítica de Politzer (1928/1998) à psicologia e à metapsicologia freudiana). Abstraçóes são válidas na medida em que favorecem essa compreensão, como, por exemplo, as pesquisas da biologia que visam as funçôes orgânicas ou vitais no sentido restrito dos termos, isto é, enquanto recortes que visam apenas o funcionamento ou as relaçóes internas do corpo. Mas é preciso entendê-lo na vida que ele porta e realiza, reintegrá-lo em seu movimento no mundo, do qual os termos "realidade orgânica" ou "psíquica" são abstraçôes.

\section{O afeto, a metafísica moderna, a medicina e a psicologia ocidentais}

Pode-se dizer que tudo que é, é em relações e que a própria definição de cada ser particular encontra-se na sua relação com os outros, o que é uma maneira de não separar a singularidade da totalidade onde ela é. Portanto, que cada ser é mais na sua relação com os outros do que como realidade isolada a partir da qual, supostamente, entraria em relação com outras realidades que lhe seriam exteriores. Em síntese, que tudo o que é já é constituído na sua relação com as outras coisas ou realidades. Nesse sentido, por exemplo, Deleuze-Guattari (1980/1997, p. 42), 
comentando Spinoza, afirmam que o que define um corpo em geral são suas relaçóes de forças, que significam sua capacidade de afetar e de ser afetado, ou ainda: "o poder de ser afetado é como uma matéria da força, e o poder de afetar é como uma função da força” (Deleuze, 1986/1998, p. 79). A força, pois, como a essência dos corpos - mas o importante é frisar que não há forças isoladas, elas são sempre em relaçóes com outras forças, ou seja, são "afectos", que é o que define suas qualidades, e, consequentemente, a do próprio corpo, isto é, seu estado ou situação no mundo (os autores grifam "afecto" para simbolizar um estado geral e mais amplo do que "afeto", que representa sua manifestação enquanto percebida).

Ora, a epígrafe com que iniciamos este trabalho destaca a percepção enquanto campo primordial para a realidade humana. Nesse caso, se tudo é em relaçâo, de modo que o "entre" uma coisa e outra faz parte da realidade de cada ser individual, na realidade humana esse "entre" se destaca como percepção, e por isso Merleau-Ponty diz que "apenas as relaçóes contam para o homem" (Merleau-Ponty, 1945/1994, p. 612). É sua maneira de dizer que o homem é um ser no mundo (Heidegger, 1927/1989). Mas, sobretudo no caso de Merleau-Ponty, o sentido no entremeio das coisas não se abstrai da atividade do próprio corpo. $\mathrm{E}$ com isso passamos propriamente ao estatuto das relaçóes de sentido, uma vez que é aí que a existência humana se joga, ou é o que importa para nós.

Merleau-Ponty (1945/1994) destaca o corpo como um arco intencional de sentidos e assim faz dele a ocasião da abertura e do jogo da existência humana, o que significa, mais precisamente, numa dimensão aquém e mais ampla do que a da consciência que acompanha e se confunde com os atos explícitos de pensamento, que era onde Descartes (1641/1983) localizava a essência do eu, fazendo do corpo, ao contrário, um mecanismo desprovido de ideias ou intencionalidade. Em síntese, para Merleau-Ponty, o corpo, e não o pensamento, ocupa o lugar de sujeito no mundo, e será a sede natural da consciência. Uma consciência, pois, antes de tudo perceptiva e motora e não enquanto pensamento (pensamento de ver, de sentir, de fazer, etc., como em Descartes, 1641/1983). Ou ainda, essa consciência enquanto corpo é antes de tudo irrefletida, pois é nas coisas ou enquanto atividade, antes de refletir sobre seus atos.

Daí também o destaque, por Merleau-Ponty (1945/1994), da noção de esquema corporal, que significa a presença do mundo ao corpo enquanto campo de suas açóes. Quer dizer, o sentido do mundo que trazemos nas pernas, nos braços, nos olhos, em nossos movimentos ou estados de repouso.

Anos depois da Fenomenologia da percepção (Merleau-Ponty, 1945/1994), ainda privilegiando e explorando a noção de esquema corporal, numa comparação com o mundo dos animais (Umwelt - meio ambiente), Merleau-Ponty (1956- 
1960/2000) diz que, ao contrário destes, no homem seu Umwelt não lhe é dissimulado. Mas isso, antes de significar consciência de si e do mundo à sua frente, à diferença dos animais, representa o maior ou menor afastamento do saber do corpo em relaçáo ao seu saber do mundo, onde ele é. Quer dizer, quanto mais sei o mundo à minha volta, mais implícito é o meu saber ou consciência do corpo próprio e, na direçáo inversa, quanto mais me volto para o próprio corpo, é o mundo que passa à condiçáo de horizonte implícito de minhas açôes ou de meu estado atual.

Ora, esse afastamento de um e outro (corpo e mundo), que não desfaz sua relação, ou, antes, que a torna possível, "é o inverso da identificação que obtenho por movimento: wahrnehmen (perceber) e sich bewegen (mover-se)" (Merleau-Ponty, 1956-1960/2000, p. 349). Ou seja, no movimento estreita-se a relaçáo entre corpo e mundo, ou se unifica efetivamente o que aparece como relação à distância, meu corpo e o mundo, embora tal unidade náo deixe de trazer ainda o mundo enquanto fundo distante e a sensação singular de meu corpo, que é o que mantém ainda seu caráter relacional. Ou ainda, o espaço que representa a percepção enquanto presença do mundo ao meu corpo ou do meu corpo enquanto ser no mundo aproxima-se numa identificação que, se não se perde ou se encerra em si mesma, é porque o mundo enquanto fundo ainda se mantém em torno do movimento do meu corpo ou de minha ação.

A linguagem também é, em Merleau-Ponty (1945/1994), encarnada nas atividades do corpo próprio, e seus significados fazem parte do sentido do próprio comportamento, ou, como também evidenciou Wittgenstein (1987) a partir de outra perspectiva filosófica, fazem parte de uma forma de vida.

Segundo Merleau-Ponty (1945/1994), ao contrário de ser fruto de um pensamento que, através do corpo e para fins de comunicação, traduziria em palavras ideias já possuídas ou pensadas, a linguagem é a realização do próprio pensamento, de modo que é o corpo que se articula através da fala ou da escrita para significar, e nesse sentido pensar, através de suas relaçóes com os outros. Por isso Merleau-Ponty (1945/1994) diz que a linguagem é um gesto e seu significado, um mundo. Ao contrário de representar ideias puras do pensamento, os significados das palavras encontram-se no contexto lógico de nossas açóes.

É ilustrativo, nesse sentido, o modo como o autor (Merleau-Ponty, 1945/1994) descreve a compreensão do gesto do outro, que não é compreendido como a percepçáo da cor de um tapete, por exemplo, mas na medida em que meu corpo esposa o sentido do comportamento do outro, como se a intenção do outro habitasse meu próprio corpo. O difícil, diz Merleau-Ponty (1945/1994), é não confundir essa compreensão com a de um ato intelectual. Não compreendo o comportamento do outro através da interpretação de ideias, mas na medida em 
que sou capaz de assumir com o próprio corpo o sentido do que o outro faz. Por isso o autor diz que, se ocorre a uma criança assistir ao intercurso sexual de adultos, a cena lhe parecerá bizarra enquanto ela não for capaz de assumir com o próprio corpo o sentido do mesmo comportamento. Ou ainda, como diz Merleau-Ponty (1949-1952/1988), um bom ator é aquele capaz de secretar com o próprio corpo os significados de seu texto; palavras são expressáo do sentido de um corpo e só são compreendidas na medida em que assumidas (virtualmente) pelo outro também (ouvinte ou leitor). Ou, de forma geral, como diz Wittgenstein (1987, p. 595), o difícil na compreensão de uma língua estrangeira, em última instância, não é a dificuldade de tradução de palavras, mas se encontrar nelas. É a dificuldade de toda tradução, porque o significado das palavras realiza-se no contexto de uma vida, é uma forma de vida. Em última instância, como diz Merleau-Ponty (1945/1994), só se vive uma língua, porque não se pode viver dois mundos a uma só vez, daí a experiência de quase "loucura" daqueles que vivem a passagem de uma para a outra. Em síntese, retornando ao sentido da epígrafe inicial, é no mundo em que nos encontramos, isto é, no sentido do que fazemos e na forma como sentimos, que esposamos ou rejeitamos o sentido do comportamento uns dos outros. Note-se, portanto, que no caráter da percepção, em Merleau-Ponty (1945/1994; 1964), se define a centralidade do sentido da experiência humana, é da ordem da atividade do corpo.

Ressalte-se, todavia, que em Descartes (1641/1983) a Antropologia encerra uma ambiguidade essencial, na medida em que as duas substâncias reveladas por sua metafísica, res cogitans e res extensa, encontram-se unidas de fato, a ponto de constituírem uma unidade confusa além da compreensão do entendimento humano. Isto é, se, para Descartes (1641/1983), pode-se conhecer com clareza (o que náo significa facilidade) o corpo enquanto mecanismo de relaçóes físicas - como ação e reação de suas partes entre si e com os outros corpos - e, em contrapartida, o pensamento enquanto produção de ideias, isso não significa que o homem seja a simples soma dessas duas partes, pois elas se confundem formando uma unidade sui generis, daí o termo união substancial. De forma que, como observa Lebrun em nota (Descartes, 1641/1983, p. 136), se a metafísica cartesiana é dualista (de direito posso conceber como substancialmente distintos corpo e espírito), sua antropologia não o é, pois, de fato, "sou totalmente corpo e totalmente espírito", o que representa um desafio à compreensão da Antropologia contemporânea.

Em outros termos, encontramos em Descartes (1641/1983) o programa de dois tipos de pesquisa que recortam a realidade humana sob duas perspectivas diferentes - uma que trata do corpo físico e outra que trata do espírito, ou, em 
termos atuais, uma que trata de processos físico-químicos, isto é, da ação, reação, composição ou divisão de um corpo (ou partícula) sobre outro, e a outra que trata dos processos psíquicos, isto é, da ação, reação, composição ou divisão de um sentido sobre outro.

Ora, o sentir ou o afeto encerram a uma só vez as duas perspectivas, pois há um sentido com determinado grau de intensidade, ou não há sentido percebido que não implique alguma sensação, como não há sensação sem algum sentido percebido. Ou seja, no sentir ou no afeto encontram-se reunidos, em termos cartesianos, corpo e alma, e por isso compreendê-lo, segundo Merleau-Ponty (citado por Saint Aubert, 2004, p. 23), é compreender tudo, uma vez que, assim, não apenas se desfaz o enigma cartesiano (o da união substancial) como também se elucidam os fundamentos ou a origem da abertura do Ser para nós, pois, também como diz Heidegger (1927/1989), a abertura ao Ser é sempre em determinado estado humor, que, ao contrário de ser apenas corolário afetivo do sentido, é constitutivo dele, isto é, faz parte da própria abertura. Ou ainda, como dizia Hume (1739/2009), sem paixão a percepção seria a tal ponto indiferente que não seria suficiente para um sentido se destacar sobre qualquer outro. Perceber, portanto, já é se afetar, o que implica sempre um interesse vital.

Também poderíamos dizer que, a partir da metafísica moderna, da qual Descartes é um exemplo ilustrativo, duas linguagens diferentes se conjugam no próprio homem sem constituírem uma unidade propriamente, na medida em que representam duas naturezas distintas, sem termo comum para sua ligação, que, no entanto, é pressuposta ou reconhecida de fato. O exemplo da análise do membro fantasma, por Merleau-Ponty (1945/1994), é bastante ilustrativo desse ponto. No caso, embora amputado fisicamente, o membro ainda mantém certa presença na vida do paciente, que persiste em sua maneira habitual de ser no mundo antes da sua amputação, ou, segundo a terminologia mais específica de Merleau-Ponty, persiste em seu esquema corporal habitual. De fato, o paciente só conta com o membro amputado evitando situaçôes que revelariam sua ausência. Ora, a presença do membro fantasma é tipicamente atribuída pela literatura a um fator psicológico na vida do sujeito, pois não se justifica, segundo os padrōes da fisiologia, como a ausência de estimulação nervosa do membro poderia provocar a sensaçáo de sua presença na vida do paciente. Ou ainda, uma explicação tipicamente física ou fisiológica não é suficiente para explicar tal fenômeno. Por outro lado, a ausência do coto, no referido caso, é suficiente para desfazer o fenômeno, o que significa que também é preciso um mínimo de substrato fisiológico para que ele se produza. Ou, como diz Merleau-Ponty, é preciso que a vida continue passando por ali e, portanto, não se pode dizer que 
se trata apenas de um fenômeno psicológico. Cartesianamente, então, fala-se de um fenômeno de causalidade mista, o que, enfatiza Merleau-Ponty, se por um lado é amplamente reconhecido enquanto fato, por outro é obscuro em seu entendimento, pois, tal como em Descartes, não se compreende como uma ordem pode atuar sobre a outra, isto é, como a ordem física ou fisiológica, de explicações causais impessoais, pode atuar sobre a ordem psíquica, que implica a vontade e a história pessoal do indivíduo. Na referida obra (Fenomenologia da percepção), é justamente através da noção de existência que Merleau-Ponty $(1945 / 1994)$ procura o terreno comum de onde nossas representaçóes psicológicas ou objetivas surgem como linguagens específicas e parciais. $\mathrm{Ou}$, mais precisamente, Merleau-Ponty procura, através da descrição fenomenológica do corpo vivo, o que já implica sua fisiologia, mostrar sua abertura e iniciação enquanto ser no mundo.

Mas não é assim que tradicionalmente explicamos nosso comportamento, porque o fazemos de forma cartesiana - é contra essa forma cartesiana de pensar que o pensamento de Merleau-Ponty se insurge.

De fato, nas sociedades ocidentais, a medicina cuida do homem através da intervenção física em seu corpo, procurando recuperar ou promover sua saúde ou bem-estar. O que significa que é ao homem integral que visa o tratamento médico, ainda que sintomas como a dor ou mal-estar sejam tratados apenas como indicativos de uma disfunção orgânica que a intervençáo médica deve resolver, restituindo o corpo ao seu estado de normalidade (normalidade que, como ressalta Canguilhem (1966/2002) representa o estado adequado para a atividade vital do organismo, ou para o melhor desempenho de suas atividades, o que a doença, em contrapartida, compromete ou diminui). O importante é frisar que, de um ponto de vista estritamente físico, não há corpo doente, ou não existe doença, e um relógio quebrado, como dizia Descartes (1641/1983), obedece às mesmas leis físicas que um relógio que marca as horas corretamente. Ou seja, enquanto um corpo físico pode apenas se transformar, um corpo ou organismo vivo pode sofrer e morrer. Ora, a medicina ocidental, de um ponto de vista teórico ou epistemológico, pode se reduzir cada vez mais à técnica porque os aspectos psicológicos da relação do paciente com o mundo e o próprio médico (termos que já representam uma visão dividida do homem) passam para um campo em que sua linguagem ou potência profissional são inoperantes. Isto não significa que tais aspectos não interfiram de forma positiva ou negativa sobre o paciente, mas que essa atuação escapa da compreensão e técnica da medicina ocidental, não fazendo parte propriamente da formação dos profissionais, ou, senão, apenas secundariamente como um complemento que reconhece sua im- 
portância, mas que em si mesmo não justifica a presença da medicina em nossa sociedade. Ou seja, se a formação e a prática médicas podem ser cada vez mais tecnicistas, deixando de lado os aspectos psicossomáticos da saúde e da doença (lembrando sempre que esse termo já implica uma visão dualista da realidade humana, ainda que buscando unificá-la), é porque é essa perspectiva que as define epistemologicamente.

Vale acrescentar, nesse sentido, que o tratamento médico, em particular no hospital, pode ser não apenas fator de vida, mas também de doença e morte. Podemos ilustrar isso através de uma analogia com um caso clássico na história da medicina, mas desta vez destacando o outro aspecto da dualidade de que estamos tratando. Foi antes da descoberta das bactérias por Pasteur (Foucault, 1979). Os médicos e os hospitais, entâo responsáveis por curar, transmitiam as doenças de um paciente ao outro através de bisturis ou instrumentos contaminados, que não eram limpos ou esterilizados entre um procedimento e outro; promoviam, assim, a morte dos pacientes, nesse caso através de um agente físico, e a descoberta de Pasteur desfez a inocência de que pareciam gozar e ao mesmo tempo lhes concedeu outra, através dos exames laboratoriais, como uma nova expressão do aumento de potência da própria medicina. Talvez um dia os fatores psicossomáticos sejam mais esclarecidos, e também a inocência, que parece existir hoje nessas relações marcadamente técnicas entre médicos, hospitais e seus pacientes, assim como eram inocentes antes de Pasteur aqueles que manipulavam bisturis contaminados, seja desfeita, e o que hoje é considerado boa medicina seja de alguma forma também ligada a um fator de morte e não de vida. É o descuido dos fatores emocionais na saúde ou na doença que em parte provoca a questão da psicossomática, fazendo lembrar que o homem é uma totalidade entre "corpo" e "alma", o orgânico e o psíquico.

Por outro lado, há em nossa sociedade uma psicologia que cuida do homem através da intervenção em suas relações de sentido, que, naturalmente, comportam estados de sofrimento, bem-estar, tristeza ou alegria. Ou seja, mais uma vez é ao homem completo, a uma só vez corpo e espírito, que sofre ou é feliz, que visa a terapia; e o difícil mais uma vez, pressuposta essa divisão, é compreender a relação entre o orgânico e o psíquico.

Não cabe, aqui, explorar os diferentes tipos de psicologia ou práticas psicoterápicas em nossa sociedade. O próprio Freud (1893/1968) evidenciou, através das psicopatologias, que o nosso corpo comporta zonas de fantasia e simbolização na produção de si mesmo ou do próprio comportamento; que uma histérica náo mente, no sentido comum da palavra, na medida em que, de fato, o drama de sua vida se transforma em seu corpo, e por isso a paralisia 
de um braço, num dos casos de histeria tratados por ele, mesmo contrariando as leis da neurofisiologia, não deixa de ser verdadeira, como também demonstram, de forma geral, o efeito placebo e os fatos da antropologia a respeito da eficácia simbólica sobre o corpo daqueles que partilham do mesmo sistema de signos (Mauss, 1950/1999; Lévi-Strauss, 1958/2003). Mas também é notório (Merleau-Ponty, 1945/1994) que a cura não passa por uma decisão de ideia ou compreensão cognitiva, mas quando o significado de seu drama, expresso ou de alguma forma conhecido em terapia, é vivenciado ou assumido como próprio, isto é, em sua relação corporal com o mundo e os outros. Como dissemos, através da noção de esquema corporal é todo um arco intencional de sentidos vitais que se encontra em jogo. Abordamos essa questão com o caso do membro fantasma - Merleau-Ponty também destaca um caso de afonia histérica, na mesma obra, e, de fato, toda sua obra visa à revisão dos quadros de pensamento que herdamos da metafísica moderna, o que o autor procura fazer também através da própria psicanálise. Mas, como vimos com o caso do membro fantasma, isso não elimina o problema de compreensão da relação entre duas ordens de explicação dos fatos, objetivos, por um lado, e subjetivos ou pessoais, por outro. Duas ordens que coexistem e se misturam em nossas práticas sociais. Tal como dizia Descartes (1641/1983) a respeito da união substancial entre corpo e alma, vivida, de fato, não compreendida, de direito.

\section{Consideraçóes finais}

Após essa apresentação de perspectiva mais ontológica ou epistemológica sobre a situação da medicina e da psicologia em nossas vidas, gostaríamos de encerrar com uma perspectiva mais política ou pragmática sobre as mesmas, não no sentido de uma contraposição, mas de uma maior abertura à sua problemática.

Ou seja, se até aqui indicamos as possíveis consequências que um determinado regime metafísico pode ter em nossas vidas, finalizamos lembrando o quanto ele é importante, no sentido estrito de que é com ele que organizamos nossa forma de vida, ou, simplesmente, é com ele que vivemos. Nesse sentido, a metafísica de uma época, antes de ser uma especulação filosófica qualquer, expressa uma forma de vida; nasce em seu seio para reproduzi-la ou modificá-la, mas sempre de forma engajada, isto é, enquanto atividade sua e não conforme uma ideia popular, como se estivesse no "mundo da lua". Daí a importância da questáo política, ou das formas histórico-sociais concretas através das quais reproduzimos e modificamos nossas formas de vida. Por isso, avaliar quais as consequências dessa divisão 
epistemológica operada pela modernidade em nossas vidas não é tarefa simples, já que envolve outras circunstâncias que não são necessariamente decorrentes dela, ou cujas consequências ontológicas não são necessariamente unívocas ou lineares (Le Breton, 2011, p. 290, destaca a heterogeneidade da qualidade dos serviços hospitalares, segundo a particularidade de cada grupo ou chefe de serviço; mas chamamos a atenção, sobretudo, para as condiçóes político-sociais desses serviços: carga horária de trabalho, remuneração, sistemas e planos de saúde, tempo disponível de atendimento, mercantilização da medicina, etc.). Ou seja, não é porque se entende de forma dualista a realidade humana que necessariamente sua consequência tenha que ser danosa à vida, embora essa ideia também não possa ser afastada por princípio, tal como desenvolvemos em nosso percurso. Aliás, como fizemos notar no artigo, se a compreensão metafísica do homem é dualista em Descartes, sua Antropologia não o é. Nesse sentido, podemos repetir a questão: em que medida é possível um tratamento médico adequado sob a perspectiva de um corpo objetivo, sabendo-se que este é, na verdade, uma pessoa? Adequado, pois, na medida em que considera primordial a totalidade do homem e não apenas o recorte pelo qual a medicina interfere em sua realidade? Por outro lado, em que medida é possível haver hoje uma interferência em nossos processos vitais à parte dessa visão mais objetiva do mesmo, tal como praticada pela medicina ocidental? Generalizando, a mesma questão se aplica à visão cartesiana de mundo, que o transforma num grande Objeto (Merleau-Ponty, 1960/1984). Sabemos, nesse sentido, que essa metafísica é o espírito da técnica ocidental, ou que a técnica está no coração da ciência moderna (Heidegger, 1938/2001), que fortalece e estimula a atividade de dominação e exploração da natureza pelo homem, o que, se por um lado ocasionou um grande desenvolvimento da capacidade do homem de produzir a própria vida, por outro também representou danos a ela e uma crescente ameaça à mesma.

De qualquer forma, uma reforma sobre a concepçáo da realidade humana (Antropologia), que também pressupóe, pois, uma concepção geral da realidade (Ontologia), implica mudanças nos sentidos de nossas experiências, isto é, de nossas práticas e atividades linguísticas diárias, na medida em que não se troca de visão de mundo "do dia para a noite". Afinal, como fizemos notar no início, não se trata de ideias abstratas, mas do modo como somos no mundo. É no modo como vivemos, como construímos nosso mundo ou realizamos nossas vidas que se encontram os sentidos de nossa metafísica e de nossas profissões, e é portanto aí, cotidianamente, que utilizamos suas potências e enfrentamos seus limites ou paradoxos, até que um dia se encontre alterada profundamente nossa visão de mundo, ou, mais concretamente, nossa forma de vida, com novos problemas e 
desafios. Isto é, questôes metafísicas não se restringem ao campo da filosofia, que antes expressa os sentidos e paradoxos da nossa vida social, lugar da verdadeira batalha e encaminhamento dessas questôes.

\section{Referências}

Canguilhem, G. (2002). O normal e o patológico. Rio de Janeiro: Forense Universitária (Originalmente publicado em 1966).

Chalmers, A. (2000). O que é ciência, afinal? São Paulo: Brasiliense.

Descartes, R. (1983). Meditaçôes. In: Descartes (pp. 83-142). Coleção Os pensadores. São Paulo, Abril Cultural (Originalmente publicado em 1641).

Deleuze, G. \& Guattari, F. (1997). Mil platôs - capitalismo e esquizofrenia, v. 4. Rio de Janeiro: editora 34 (Originalmente publicado em 1980).

Deleuze, G. (1998). Foucault. São Paulo: Brasiliense (Originalmente publicado em 1986).

Foucault, M. (1979). A casa dos loucos. In: R. Machado (Org.). Microfisica do poder (pp. 113128). Rio de Janeiro: Graal.

Freud, S. (1968). Algunas consideraciones com miras a un estudio comparativo de las parálisis motrices orgánicas e histéricas. Obras completas, vol. I. Madri: Biblioteca Nueva (Originalmente publicado em 1893).

Heidegger, M. (1989). Ser e tempo. Petrópolis: Vozes (Originalmente publicado em 1927).

Heidegger, M. (2001). L'époque des conceptions du monde. In: Chemins qui ne mènent nulle part (pp. 99-146). Paris: Gallimard (Originalmente publicado em 1938).

Hume, D. (2009). Tratado da natureza humana. São Paulo: Edunesp (Originalmente publicado em 1739).

Kuhn, T. (2009). A estrutura das revoluçôes científicas. São Paulo: Perspectiva (Originalmente publicado em 1962).

Le Breton, D. (2011). Antropologia do corpo e modernidade. Petrópolis: Vozes.

Lévi-Strauss, C. (2003). Antropologia estrutural, v. 1. Rio de Janeiro: Tempo Brasileiro (Originalmente publicado em 1958).

Mauss, M. (1999). Sociologie et anthropologie. Paris: PUF (Originalmente publicado em 1950). Merleau-Ponty, M. (1964). Le visible et l'invisible. Paris: Gallimard.

Merleau-Ponty, M. (1984). O olho e o espírito. In: Merleau-Ponty (pp. 86-111). Coleção Os Pensadores. São Paulo: Abril Cultural (Originalmente publicado em 1960).

Merleau-Ponty, M. (1988). Merleau-Ponty à la Sorbonne - Résumés de Cours - 1949-1952. Grenoble, France: Cynara.

Merleau-Ponty, M. (1994). Fenomenologia da percepção. São Paulo: Martins Fontes (Originalmente publicado em 1945). 
Merleau-Ponty, M. (2000). A natureza - notas de cursos no Collège de France, 1956-1960 (texto estabelecido e anotado por Dominique Séglard). São Paulo: Martins Fontes.

Politzer, G. (1998). Crítica dos fundamentos da psicologia - a psicologia e a psicanálise. Piracicaba: Unimep (Originalmente publicado em 1928).

Saint Aubert, E. (2004). Du lien des êtres aux éléments de l'être-Merleau-Ponty au tournant des années 1945-1951. Paris: Librairie Philosophique J. Vrin.

Sartre, J.-P. (1976). L'être et le néant. Paris: Gallimard (Originalmente publicado em 1940).

Wittgenstein, L. (1987). Investigaçôes filosóficas. Lisboa: Fundação Calouste Gulbenkian.

Recebido em 15 de janeiro de 2011

Aceito para publicação em 13 de junho de 2011 